AUTOR

Ana Luiza

Valverde da

Silva*

analuizavalverde@ gmail.com

* Doctoranda en la

Universidad de Valencia

\section{La cultura y la mitología en el cine brasileño de Glauber Rocha}

\author{
A cultura e a mitologia no cinema de Glauber Rocha
}

The featured of culture and mythology in the Brazilian Glauber Rocha movies

\title{
RESUMEN
}

Glauber Rocha propone dos películas que reflexionan sobre la distribución social y el sistema económico vigente en el Brasil de los años 1960. Deus e o diabo na terra do sol, de 1964, se integra en el contexto de la estética del hambre y es signo del cine revolucionario, vanguardista y con una visión cinematográfica anterior al golpe militar. En cambio, Antonio das Mortes, de 1969, nace en medio de las transformaciones desencadenadas por el movimiento Tropicália y de la represión de la libertad de expresión creada por la dictadura brasileña. Esa investigación está fundamentada en la representación empleada por Glauber Rocha para destacar la cultura y la mitología en ambas películas como una forma de reivindicación social.

\section{RESUMO}

Glauber Rocha apresenta dois filmes que refletem a distribuição social e o sistema econômico vigente no Brasil durante a década de 1960. O filme Deus e o diabo na terra do sol, 1964, está inserido no contexto da estética da fome, e é signo do cinema vanguardista e revolucionário anterior ao golpe militar. Por outro lado, 0 dragão da maldade contra o santo guerreiro (Antônio das Mortes), de 1969, nasceu em meio ao movimento Tropicália e a repressão da liberdade de expressão criada pela ditadura militar brasileira. Essa pesquisa está fundamentada na representação usada por Glauber Rocha para destacar a cultura e a mitologia em ambos os filmes produzidos em meio a este difícil momento político e social que vivia o povo brasileiro.

\section{ABSTRACT}

Glauber Rocha presents two films that reflect the social distribution and the social system regent in Brazil during the 60s decade. The film Black God and White Devil, 1964, fits into the context of hunger aesthetics, and it is a sign of the vanguard cine, a revolutionary instrument with a point of view before the military coup. On the other hand, the film Antonio das Mortes, 1969, born in the midst of the changes triggered by the Tropicália movement and the repression of freedom of speech created by the Brazilian military dictatorship. The research is based on the representation used by Glauber Rocha to highlight the culture and mythology in both filmographies in this difficult political moment. 


\section{Introducción}

Glauber Pedro de Andrade Rocha (1939 - 1981) nació en Vitória da Conquista (Bahía, Brasil). Era estudiante de Derecho cuando se enamoró del cine y se convirtió en uno de los más aclamados cineastas brasileños de su tiempo. Su experimentación con el lenguaje cinematográfico no encontró límites a la hora de reafirmar la nacionalidad brasileña. Esto le llevó a la búsqueda del "brasileño puro" (sin influencia internacional). Por ese motivo, sus temáticas abordan asuntos antropológicos tan complejos como la cultura, la mitología y el folclore.

Glauber Rocha fue muy crítico con las instituciones establecidas y con el sometimiento económico y político de las clases populares. De esta forma, encuentra en la cultura popular todas las variantes que determinarán su lenguaje cinematográfico. Rocha reclama el acercamiento y la representación del pueblo en la pantalla como necesarios para hacer del cine un arma política, tanto nacional como internacional. Los precursores de este tipo de cine conciben la cámara cinematográfica como una herramienta que les permite plasmar sus idea agitadoras. Sus películas están marcadas por un amplio trasfondo político que expresa la crítica de Rocha hacia la violencia histórica de Brasil y hacia la dependencia económica y política de países extranjeros.

PALABRAS CLAVE

Mitología; cultura; Glauber Rocha

PALAVRAS-CHAVE

Mitologia; cultura; Glauber Rocha

KEYWORDS

Mythology; Culture; Glauber Rocha

En Brasil, la década de 1960 estuvo marcada por la fuerte represión impuesta por la dictadura. El presidente progresista João Goulart había proclamado sus intenciones de aplicar políticas de izquierda en el país: avances en los derechos civiles, oposición a la privatización del petróleo y creación de la Superintendencia de Política Agraria (Avellar, 2002:9). En ese momento la concepción del cine brasileño era de revolución y afirmación de la cultura nacional. La película Deus e o diabo na terra do sol se estrenó el 13 de marzo de 1964, en Río de Janeiro, en un periodo convulso debido a la crisis económica y política que vivía el país. Se percibía un espíritu optimista por las manifestaciones de izquierda y de las clases populares, así como por la promesa de reformas de base del gobierno João Goulart. Con el golpe militar, la censura pretendió destruir esa película, y por ese motivo la película fue sacada del país de manera clandestina. Así, Glauber Rocha consiguió mostrar Deus e o diabo na terra do sol en el exterior y ganar la Palma de Oro del Festival de Cannes, en 1964. Con motivo del estreno se celebró un debate, grabado por Alex Viany, en el que Rocha decía:

No es un logro mío, individual: creo que la película es el logro de toda la consciencia cultural propiamente dicha que tiene el Cinema Novo (...) las condiciones culturales y políticas de Brasil y la feliz coincidencia histórica con el nivel de concienciación constituyen la llamada coincidencia histórica inevitable (Rocha, 1964)'1.

La dictadura brasileña censuró duramente la libertad de expresión. El 13 de diciembre de 1968, la administración militar del presidente Costa e Silva promulgaba el Ato Institucional n 5 (Al-5), por el cual cualquier empresa de comunicación debía tener los guiones previamente aprobados y sometidos a inspección por agentes autorizados del gobierno. Esa ley también alcanzó al arte y los movimientos culturales. En ese mismo año Rocha rodaba la película Antonio das Mortes en la ciudad de Milagres, en el interior de Bahía. El Al-5 restringió la libertad civil y de expresión, acto que acabaría con el movimiento Tropicalista, iniciado en la segunda mitad de 1967. Dentro de ese cuadro de inestabilidad social se estrena la película Antonio das Mortes, revolucionaria y vanguardista para su tiempo.

En este período nos movemos de una conciencia de arte a las acciones provocativas sobre la base de las estrategias de agresión y collages pop que marcaron la politización en Brasil. La ironía de artistas favorece la sociedad de consumo como una meta, mientras que en Brasil, una nueva manera de entender el tema de la industria cultural y nuevo nivel de mercantilización del arte, la información y el comportamiento de los jóvenes, incluyen la 
rebelión (Xavier, 2001: 29).

En 1969, Glauber Rocha escribe el texto Tropicalismo, antropología, mito, ideograma en el que expresa la influencia del movimiento Tropicália en Antonio das Mortes. La película constituye un gran teatro con mucha ironía sonora y el colorido del tropicalismo, donde la vía revolucionaria del pueblo está representada por Santa Bárbara (Rosa Maria Penna), Negro Antão (Mário Gusmão), el cangaceiro Coirana (Lorival Pariz), y la unión intelectuales-pueblo, provocada por el profesor (Othon Bastos).

Tropicalismo es la aceptación del subdesarrollo; por lo que es la película antes y después del tropicalismo. Ahora ya no tenemos miedo de confrontar la realidad brasileña, nuestra realidad, en todos los sentidos y todas las profundidades. Por eso, en Antônio das Mortes existe una relación antropofágica entre los personajes: el profesor se come a Antônio, Antônio se come al cangaceiro, Laura se come al comisario, el profesor se come a Claudia, los asesinos se comen a las personas, el profesor se come al cangaceiro (Rocha, 1981: 119).

La película causó malestar político al tratar asuntos comprometedores para la dictadura. Aborda cuestiones revolucionarias del nordeste de Brasil, hecho que marcó a Rocha como un líder de la izquierda cinematográfica. La Comisión de la Verdad $^{2}$ sospechaba que la dictadura planeaba detener Glauber Rocha, algo que no pusieron en práctica porque se exilió en 1971.

La película no es para nosotros una máscara, porque la película no hace la revolución, la película es uno de los instrumentos revolucionarios y esto debería crear un lenguaje latinoamericano, libertario y revelador (Glauber Rocha en entrevista a la revista Cine Cubano, 1971).

\section{La cultura}

Actualmente resulta complicado hablar de las definiciones de cultura, en vista de que puede adquirir innumerables significados. La cultura está conformada por todas las actividades del hombre en su espacio. En todos los modelos y con variados vínculos: sociales, religiosos, políticos, familiares, etc... Desde un punto de vista genérico, la cultura se construye sobre la base de dos lenguajes primarios. Uno es la lengua natural, utilizada por el hombre en el trato cotidiano, y la otra son los modelos clasificadores del espacio en ajeno y lejano (Lotman, 1979: 57)

La cultura también está constituida por un sistema de signos sometidos a reglas que permiten considerarla como una lengua. Jorge Lozano la define como un sistema semiótico ordenado de comunicación, que sirve para transmitir información. Siendo la cultura: a) un sistema de comunicación; b) que sirve de signo; c) estos signos están organizados (Lotman, 1979: 23). La definición de la característica fundamental de la cultura es la necesidad de subrayar la relación entre el signo y la representación. También es entendida como el lenguaje organizado en forma de textos. El lenguaje natural es el único que puede asumir una función metalingüística.

La cultura es generadora de estructuras y el lenguaje natural es el que desarrolla precisamente esa función de dar nombre, distribuir y ordenar la realidad dentro del marco de la cultura (Lozano, 1979: 25). El trabajo natural de la cultura para Yuri Lotman es organizar estructuralmente el mundo que rodea al hombre. "El mundo es un libro que espera a su lector", dice S. Mathauserovà (Lozano, 1979: 25). Al construir un modelo del mundo, la cultura construye un modelo de sí misma, son sistemas comunicativos y las culturas humanas se fundamentan en el sistema semiótico del lenguaje natural. Comprender la vida cotidiana es lo mismo que estudiar la lengua. Consiste en traducir un sector de la realidad en una de las lenguas de la cultura, por ejemplo, ver una película equivale a aprender otra lengua (Lotman, 1979: 42).

En las dos películas, Deus e o diabo na terra do sol y Antonio das Mortes, la cultura se inscribe a través del lenguaje, de la comunicación, del escenario y por su propia representación. La cultura nordestina brasileña está presente de forma muy llamativa: en trajes, personajes, lengua, música, tema narrativo y en el contexto de ambas películas. En la historia 
del pueblo que camina entre ciudades en busca de mejores condiciones de vida, y en los jagunços que asesinan a los cangaceiros.

Antonio das Mortes es menos intelectual que Deus e o diabo na terra do sol. No contempla un romance, sino una historia de rebelión social protagonizada por el pueblo y sus defensores, además del desorden que viven dichas personas como retentoras del orden social. El espectáculo cinematográfico de Deus e o diabo na terra do sol contempla la estética del hambre, mientras que Antonio das Mortes propone la cultura brasileña estipulada después de Terra em Transe ${ }^{1}$ (1967), también de Glauber Rocha. El Tropicalismo ${ }^{2}$ influenció al director en la narración de Antonio das Mortes, pues ese movimiento propició una discusión nacional en torno a la escasez, la idea de exuberancia y la ostentación.

La cultura aquí acaba por ejercer la función y el propósito de comunicar, de describir la historia vivida en la época. Las películas Deus e o diabo na terra do sol y Antonio das Mortes son un manifiesto y reivindican los derechos del pueblo. Esta es la manera en que Glauber Rocha expresa su opinión política. Utiliza el contenido para centrarse en la expresión (símbolo) y en el ritual.

\section{El signo y el significado en las películas}

Según Pierce y Morris los signos son parte del sistema primario y forman el objeto más inmediato de la semiótica. El signo contiene un código, que representa/adquiere la forma de un objeto. En la lingüística no es algo de naturaleza simplemente vocal, sino una unidad de una imagen acústica, y de un concepto. La palabra es el signo que puede ser dicho por el locutor y ser comprendido por el receptor. Al hablar se le da al signo la ayuda de un sonido articulado. Siendo el signo aquel que se muestra a sí mismo, comprendido como un significante sobre el significado. Se asocia al signo la idea de unidad, de algo que puede ser circunscrito por una totalidad, como un idioma que forma un sistema de expresión de signos. Como resultado, un signo solo no tiene el mismo valor que varios signos agrupados, y el conjunto de signos/códigos forma el texto narrativo. En ese sentido un conjunto de signos forma un sistema semiótico. El signo es el elemento base de la semiótica y la cultura. Los sistemas culturales son constituidos por el sistema modelador primario que corresponde a la lengua natural.

El acto individual del intercambio sígnico comenzó a ser considerado como el modelo de la lengua natural, y los modelos de las lenguas naturales, como modelos semióticos universales, y se tendió a interpretar la propia semiótica como la extensión de los métodos lingüísticos a objetos que no se incluían en la lingüística tradicional (Lotman, 1996: 10).

Y puede adquirir diferentes formas dentro del sistema semiótico, por ejemplo en los sistemas modeladores secundarios como la danza, la arquitectura y la literatura.

Si el signo es la unión de un significado y un significante, la comprensión recíproca es posible sólo basándose en su constancia: queriendo expresar un significado, recurro al significante que lo corresponde; escuchando o viendo un significante, sé a qué significado se refiere (Casetti, 1980: 50).

No existe una independencia entre significante y significado, al expresar uno se remite al código del otro. El concepto del significado (objeto) es idéntico en la conciencia al concepto del significante (fonética). El significante, por ser de naturaleza auditiva, se desenvuelve en el tiempo. Las señales auditivas se agrupan una a una, en un desarrollo que puede dimensionarse a través del espacio. Esto define el signo como espacial. Lo que lleva el concepto de signo más allá de lo lingüístico, como por ejemplo las señales marítimas o la música. Pero también existen estructuras que no sobrepasan la dimensión del tiempo, estos son, los códigos visuales (el significado) como por ejemplo las imágenes (Casetti, 1980: 128). En las estructuras del sistema de signos, se puede utilizar el cine como un sistema espacial y temporal.

Yuri Lotman comenta que "la narración 
cinematográfica es la forma más plena del texto narrativo icónico, que une la esencia semántica de la pintura y el sintagmatismo transformacional de la música" (2000: 13). La pintura se propone ser icónica (espacial) y la música es el movimiento de desarrollo en la forma pura (temporal). Las dos películas aquí analizadas se integran en una narración temporal que aborda los problemas sociales y políticos de Brasil en la década de 1960. También contienen la representación de géneros narrativos de la literatura y de la música, que muestra las tendencias espaciales. En la película Antonio das Mortes, Glauber Rocha utiliza la música para combinar el desarrollo espacial y temporal:

Mire aquí Antônio das Mortes, mire la evidencia de tortura. Cogí un pau de arara pues estaba pensando convertirme en rico algún día. Pero cuando llegué a Minas Gerais pronto me encontré esclavo. Me vendieron al servicio en las matas del Mato Grosso. Sólo los fuertes podían ponerse de pie. Y los débiles se rindieron. Llegó la ira y el deseo... caminé hacia Bahía. Al llegar a Juazeiro vi a un anciano que vendía a su hija por cinco contos de réis. Entonces la robé y fui hacia el interior del país hasta la frontera de Alagoas. Cuando lo vi llegar dije, ahí viene el hombre que difunde la miseria. Y a él le entregué las uvas de mi abuela. Yo le he bautizado con el nombre de Coirana, la serpiente venenosa, y salimos los dos por los caminos, por la basura a recoger a los desafortunados (Cangaceiro Coirana en la película Antônio das Mortes, 1969).

El cangaceiro canta para Antonio das Mortes el poema que describe su propia trayectoria. Aunque la letra sea temporal, la música es espacial pues existe/resiste a través de los años. $Y$ como explica Lotman, "en la construcción del texto narrativo sobre la base de la lengua natural, las palabrassignos se reúnen en cadena conforme a las reglas de la lengua dada y al contenido del mensaje" (Lotman, 2000: 10). En la música, la lengua natural está levemente modificada respecto a la gramática correcta. El realizador, al inscribirla, mantiene el habla cotidiana propia de los pueblos del sertão brasileño: lo hace para conservar la cultura local. A través del sistema cultural el cineasta agrupó un conjunto de sentidos (visual, auditivo $y$ representativo) que juntos forman la semiosfera de la película. Lo mismo ocurre en Deus e o diabo na terra do sol, donde la música narra los acontecimientos y proporciona la unión de esa clase de sentidos.

Manuel y Rosa vivían en el sertão... trabajando la tierra con las propias manos. Hasta que un día, para bien o para mal, entró en sus vidas San Sebastián. Tenía bondad en los ojos y a Jesucristo en el corazón (Canción de Deus e o diabo na terra do sol, 1964).

Francisco Casetti explica que "el signo se emite con el deseo concreto de significar algo, y el que lo recibe lo descodifica, en base a la premisa de la existencia de tal deseo" (Casetti, 1980: 348). Glauber Rocha exaltó a través de numerosos signos la cultura brasileña. El significado de cada código está expuesto como una clase de sentidos culturales y no como significado singular. Abajo se presenta un listado con algunos ejemplos encontrados en las películas.

Uno de los signos más destacables es el del cangaceiro. La palabra cangaceiro deriva del cangaço, que fue un movimiento revolucionario. El objetivo era reivindicar justicia por la falta de empleo y vengar la hambruna del pueblo, a través de la invasión de las residencias de los terratenientes. El cangaceiro era el hombre que formaba parte de ese movimiento revolucionario. Lampião y Corisco, el último también personaje de Deus e o diabo na terra do sol, fueron famosos cangaceiros que representaron el movimiento a principios del siglo $X X$, convirtiéndose en figuras folclóricas del nordeste de Brasil.

Antonio das Mortes, el asesino de cangaceiros, simboliza el jagunço. La palabra jagunço viene de la lengua africana Quibundo, jagun-jagun, cuyo significado es el de soldado del iorubá. En el nordeste de Brasil era normal que los terratenientes y políticos contrataran a los supuestos "soldados" para defender sus intereses personales. Actualmente, el jagunço forma parte del folclore nordestino. El personaje Antonio das Mortes se basó en el Mayor José Rufino, asesino de cangaceiro muy conocido en la ciudad de Vitória da Conquista (Bahía, Brasil), ciudad natal de Glauber Rocha. Rufino creía que al asesinar cangaceiros y 
beatos podría terminar con la rebelión anarquista. El Mayor José Rufino fue la inspiración para Rocha en ambos largometrajes. En Deus e o diabo na terra do sol dio pie a toda la segunda parte de la película, cuando Manuel y Rosa entran en el grupo de Corisco. En Antonio das Mortes, la inspiración surgió del episodio en que Rufino fue a Pernambuco para asesinar al cangaceiro Zé Crispim, sin que la policía consiguiera capturarlo (Rocha, 1981: 165). En ambas películas, Antonio das Mortes también simboliza el Diablo.

Los mitos religiosos de Dios y el Diablo están presentes en las dos películas. Según la Biblia, el carácter de Dios es símbolo de la justicia (Athos 17:31), amor (Efesios 2: 4-5), verdad (Juan 14: 6) y santidad (1 Juan 1: 5). Dios muestra compasión (2 Corintios 1: 3), misericordia (Romanos 9:15) y gracia (Romanos 5:17). Dios no sólo juzga el pecado (Salmo 5: 5), sino que también ofrece el perdón (Salmo 130: 4). Los santos son representados por San Sebastián, Santa Bárbara y San Jorge. San Sebastián desempeña el papel de misionero del Dios negro. Es conocido como el santo hombre, que a través del sacrificio ofrece el perdón a las personas. También denominado poseedor de la verdad, Sebastián es un nombre griego que significa el divino y venerable. Según la historia, Sebastián fue un mártir de Jesucristo, que murió en la persecución del emperador romano Diocleciano. En la primera tentativa de asesinarlo, Sebastián fue atravesado con flechas, pero sobrevivió. Después, fue golpeado hasta la muerte. Por ese motivo, San Sebastián es representado como un hombre cubierto de flechas. En Deus e o diabo na terra do sol San Sebastián es asesinado apuñalado por Rosa. Santa Bárbara representa a lansã, y San Jorge (Negro Antão), a Oxóssi, ambos entidades guerreras del candomblé. Los dos son soldados del pueblo, Santa Bárbara perdona a Antonio das Mortes y Negro Antão asume el puesto de San Jorge al matar el Coronel Horacio con una espada sobre un caballo blanco.

El candomblé es una religión pagana. La palabra pagana proviene del latín paganus, y alude a una persona que vive en el campo, un campesino. En el siglo IV, el Imperio Romano utilizaba el término paganus para denominar a las personas que no eran cristianos y aún creían en los antiguos dioses romanos. En la actualidad, se definen como religiones paganas aquellas religiones noabrahámicas y contemporáneas: la mayoría de las religiones orientales y las tradiciones indígenas de América, Asia Central, Australia y África. En sus películas, Glauber Rocha aborda las religiones procedentes de la esclavitud africana, como por ejemplo el candomblé y la umbanda. La religión afro-descendente candomblé, en el vocabulario quimbundo, significa "el arte curativo". Esa religión africana utiliza los orixás, y vudús (tiene más de tres millones de seguidores en todo el mundo y muchos de ellos están en Brasil). Rocha también utiliza la religión católica como símbolo de religión/poder. En Antonio das Mortes, el cineasta recurre a la imagen de San Jorge como metáfora de la victoria del bien contra el mal; o de la victoria del pueblo hambriento sobre el terrateniente oportunista.

Los rituales de las películas son prácticas del candomblé. Pero el ritual aplicado por San Sebastián en la película es el de la magia negra. San Sebastián utiliza la sangre de un niño para purificar a Rosa. Ese acto de sacrificio humano es conocido como Libelo de Sangre. Se trata de un ritual de magia negra o brujería. La magia negra puede ser una comunicación espiritual con un propósito maligno y egoísta. La brujería es una religión de fundamentos espirituales.

Las mujeres en ambos largometrajes son suministradoras de la muerte y símbolo de la fuerza. Para Rocha, las figuras femeninas son conscientes e influentes.

Se me hace difícil trabajar con personajes femeninos. Escribí varios guiones que no fueron filmados, en los que tuve dificultades para crear personajes femeninos, que están conmigo de una manera siempre consciente y ejercen una influencia moral o política (Rocha, 1981: 83).

Rosa, en Deus e o diabo na terra do sol, asesina a San Sebastián como símbolo de la liberación del espacio en el que vivía. Laura, en la película Antonio das Mortes, asesina a su amante Mattos por rabia y para demostrar remordimiento a su marido, el coronel Horacio. Ambas muertes simbolizan la furia, la ruptura violenta del cuerpo causada por el exceso de presión interior. Antonio das Mortes también muestra a Santa Bárbara, que simboliza el 
liderazgo y la fuerza del pueblo.

El signo del pueblo, que aparece en ambas películas siempre en grupo, caminando por la ciudad o por el sertão, representa a las personas que salían de sus casas en busca de trabajo y mejores condiciones de vida. Se trata de un hecho muy común en el nordeste de Brasil. Sin embargo, como es detallado por Glauber Rocha, difícilmente conseguían alcanzar sus objetivos y muchos acababan por morir de hambre, enfermos o asesinados. El pueblo también representa la reivindicación o la revolución a través del carnaval y las fiestas. A través del pueblo, en sus películas, Rocha pone de manifiesto las penurias que sufría la población brasileña en aquella época. Al mostrar la realidad como un aviso para la población brasileña, Rocha pone en evidencia su ideología y el movimiento del Cinema Novo.

Los símbolos utilizados por el realizador conforman su estilo, que en la película Deus e o diabo na terra do sol es el cine del hambre, mientras que en Antonio das Mortes ya se destaca como un cine en pos del movimiento Tropicalista y de la rebelión. En ambos casos, el objeto del director es destacar los símbolos del hambre, la violencia y el caos social que, según él, la política brasileña desarrolla.

\section{La representación mitológica de Glauber Rocha}

El mito es un estudio de la cultura y la historia. En general, el mito intenta explicar y demostrar el modo de ser de las personas y sus relaciones con otros, así como el origen de todo lo que envuelve una sociedad y su universo, como el origen del mundo, del hombre, de los animales, de las prácticas de caza, de pesca, del amor, de la medicina y de las enfermedades. Para Claude Lévi-Strauss es difícil separar la historia y la ciencia de los mitos, todo viene junto. El estudio de los mitos es el estudio de una sociedad, de sus costumbres, comportamiento, pensamiento y cultura.

El mito puede ser la manera de pensar de los pueblos. El funcionalismo es las determinantes por las necesidades básicas de la vida: subsistencia, sexuales, instituciones sociales, sus creencias, su mitología y todo lo demás (Lévi-Strauss, 1987: 35).

En la ciudad de Jardim das Piranhas (película Antonio das Mortes) los mitos son signos de la lucha y fe del pueblo. La imagen de los santos en los carteles de la procesión indica la fuerte creencia en Dios y sus santos en la guerra del bien contra el mal. El culto de la religión pagana afro-brasileña del candomblé proviene de la era de la esclavitud. El mito de Santa Bárbara y San Jorge son la creencia en que Dios está al lado del pueblo, y también junto a ellos se encuentra el folclórico personaje del cangaceiro, que lucha para vengar la desgracia de los oprimidos.

La descripción mitológica es por principio monolingüística, los objetos de ese mundo se describen a través de ese mismo mundo construido del mismo e idéntico modo. Por el contrario, la descripción no mitológica es plurilingüística, ya que lo importante es la remisión a un metalenguaje entendido como otra lengua (el proceso de traducción-interpretación) (Lotman, 1979: 112). Comprender un mito es un trabajo que necesita una visión holística de la situación. En base a la creencia social, la religión, la política y la historia se empiezan a entender el significado del mito. Cada vez más, los sentidos son integrados, principalmente con la explicación científica.

La búsqueda de significado tiene una verdad que puede ser explicada, afirma Lévi-Strauss en el libro Mito y Significado: no existe en realidad una especie de divorcio entre mitología y ciencia. Sólo el estudio alcanzado contemporáneamente por el pensamiento científico nos posibilita comprender lo que hay en ese mito (1987: 35$)$.

La mente humana y la forma en la que trabaja la conexión cerebral dan como resultado una experiencia. El modo en que la percepción humana absorbe la realidad junto con la manera en que se corresponde la mente, tiene como resultado la acción; y por ese motivo no se puede separar la ciencia del mito. Así pues, para describir un mito y su significado hay que comprender lo que llevó el mito a ser escrito. De esa manera regresamos 
a la definición de que el estudio del mito es el estudio de una sociedad, de sus costumbres, comportamiento, pensamiento y cultura. LéviStrauss pregunta “¿dónde termina la mitología y donde comienza la historia?" (1987: 65). Responde que el estudio de la historia y el de la mitología pueden caminar juntos. La mitología puede ser una continuación de la historia. Pero la mitología puede encontrase en un sistema cerrado, en cuanto que la historia está abierta a los acontecimientos.

No estoy muy lejos de pensar que en nuestras sociedades la historia sustituye a la mitología y desempeña la misma función, ya que para las sociedades ágrafas y que por tanto carecen de archivos la mitología tiene por finalidad asegurar, con un alto grado de certeza - una certeza completa es obviamente imposible - que el futuro permanecerá fiel al presente y al pasado (Lévi-Strauss, 1987: 65).

La mitología es una parte de la historia, aunque la historia continua siendo escrita todos los días y la mitología permanece estática en una parte del tiempo. Pero es imposible comprender un mito como una secuencia continua. Por ejemplo, en la semiótica, para entender un mito hay que aprehenderlo como una totalidad. El significado del mito no está ligado solo a una secuencia de acontecimientos, sino a grupos de acontecimientos, aunque tengan lugar en distintos momentos de la historia.

En la película Antonio das Mortes, Rocha utiliza la cultura popular y crea el mito del Dragón y del Santo Guerrero. El dragón está representado a través de Antonio das Mortes (en la primera parte de la película) y del coronel Horacio. El terrateniente es representado como el propietario de las riquezas de la ciudad de Jardim das Piranhas. Él proporciona alimentos al pueblo y les dice:

Yo soy un buen hombre, soy como un padre para vosotros. Pero Jardim das Piranhas es una ciudad pobre. Miradme a mí, a mi ropa y a mi casa. El gobierno me está engañando. Me prometieron enviar más alimentos, más dinero para la presa, para la medicina... pero no me enviaron nada. Yo no puedo hacer nada, no soy Jesucristo para daros comida gratis. Yo soy un buen hombre. No puedo hacer milagros. ¿Escuchasteis? Todos se van, pero esperan que haga una obra de caridad. Batista abrirá la tienda y les dará de comer: carne seca para todos. Pero recordad que es una obra de caridad... Id y decidle a todos que soy un buen hombre, yo soy un hombre caritativo (Coronel Horácio, Antonio das Mortes, 1969).

En otro momento de la película, el coronel Horacio envía a Mata Vaca y a sus secuaces para asesinar a todos los que estaban participando en la rebelión. El Santo Guerrero está encarnado por Antonio das Mortes - en la segunda parte de la película -, después de redimirse de sus pecados y luchar a favor del pueblo. Pero se representa principalmente en la figura de negro Antão, que al final asesina al Coronel Horacio desde su caballo, con una lanza. La imagen creada por Rocha es la del mito de San Jorge, uno de los santos más venerados por la Iglesia Católica (Romana, Ortodoxa y Anglicana) y símbolo de Ogum, santo del candomblé, que representa a los dioses de la guerra, la agricultura y tecnología.

La cultura popular siempre será una manifestación relativa cuando sólo inspirar un arte creado por artistas que están sofocados por la razón burguesa. La cultura popular no es lo que técnicamente se llama folclore, sino el lenguaje popular de la rebelión histórica permanente. La reunión de los revolucionarios fuera de la revolución burguesa con las estructuras más importantes de la cultura popular será la primera configuración de un nuevo signo revolucionario (Rocha, 1971).

El folclore es una forma de creación autónoma (Lozano, 1979: 16). Según Jorge Lozano, los principios semióticos fundamentales son:

a) No se da innovación lingüística sin que haya un consenso social que la acepte y la integre, y esto vale también para los otros sistemas de comunicación;

b) Cualquier sistema semiótico está sujeto a leyes semióticas generales y opera como código, pero tales códigos están vinculados a comunidades especificas (del poblado al grupo étnico) del mismo 
modo que un lenguaje genera sus sub-códigos ligados a profesiones o actividades determinadas;

c) El estudio de un código es estudio tanto de sus leyes sincrónicas como de la formación y transformación diacrónicas de estas leyes (Lozano, 1979: 16).

La comunicación social está formada por un vasto sistema de significación como los comportamientos sociales, los mitos, los ritos, las creencias, etc. (Lozano, 1979: 23). En el libro Lo crudo y lo cocido, Lévi-Strauss describe los mitos indígenas. Al hablar sobre el primer mito, el teórico explica el origen del pueblo y los significados del nombre, de los que participan en este: "Un mito puede perfectamente contradecir la realidad etnográfica a la que pretende referirse, y no obstante, tal deformación forma parte de su estructura" (1964: 51). Yuri Lotman, al disertar sobre los espacios de los nombres mitológicos, explica que estos son cerrados y pequeños. El significado de los nombres propios, en realidad, son mitológicos (Lotman \& Escuela de Tartu, 1979: 117). Son palabras que surgen de la lengua natural. El lenguaje mitológico contiene los textos-códigos que son textos escritos referentes a la realidad, pero no reales.

\section{El ritual}

Los rituales son característicos de todas las culturas y están presentes en ambas películas. En Deus e o diabo na terra do sol, el ritual aparece en el culto de exorcismo de Rosa. San Sebastián utiliza la religión pagana para persuadir a sus seguidores. Se sirve de la religión pagana umbanda, afro brasileña, como un símbolo del orixá de las florestas, y de las relaciones entre los reinos animal y vegetal. Su representación es de gran cazador, y en la floresta está marcado por el uso del arco y flecha. Glauber Rocha muestra a San Sebastián como un superviviente (a pesar de morir a manos de Rosa). La escena del ritual de Libelo de Sangre empieza dentro de una capilla. Con la mano derecha en el corazón y con la mano izquierda sosteniendo una bengala, San Sebastián habla a Manuel: "Debes decidir... ve abajo y trae a tu mujer y un niño.
Solo después de lavar el alma de Rosa, tú estarás purificado. Para reinar en la isla". Manuel camina hasta al pueblo y entre gritos proclama: "iMi mujer está poseída por el demonio! ¡Mañana caerá una lluvia de oro! ¡El sertão se convertirá en mar! ¡Y el mar se hará sertão! Sólo llegaremos a la isla si lavamos el alma de los pecadores con la sangre de los inocentes".

Manuel regresa, sosteniendo el niño en brazos, San Sebastián corta la garganta del bebe con un cuchillo y la sangre del arma se derrama sobre la cabeza de Rosa.

El ritual satánico pone a prueba la integridad de San Sebastián, que hasta el momento era conocido bajo el nombre de Dios negro. Pero después de dicho ritual, la reina duda de quién será San Sebastián. En la escena, Rosa ve una oportunidad de asesinar a San Sebastián y la aprovecha.

El espacio ritual copia de manera homomorfa el universo, $y$, al entrar en él, el participante del ritual ora se vuelve (al tiempo que sigue siendo él mismo) un espíritu del bosque, un tótem, un muerto, una divinidad protectora, ora adquiere de nuevo una esencia humana. Se extraña de sí mismo, convirtiéndose en una expresión cuyo contenido puede ser él mismo (cf. las representaciones de los muertos en los sarcófagos y los retratos "funerarios") o tal o cual ser sobrenatural. Gracias a la división del espacio, el mundo se duplica en el ritual, de la misma manera que se duplica en la palabra (Lotman, 1979: 58).

En la película Antonio das Mortes el ritual se presenta con cantos, danzas del pueblo y en la lucha del cangaceiro con Antonio das Mortes. En un culto de candomblé las personas caminan, aplauden y cantan, llevan banderas de los santos representados en la película. En la lucha del cangaceiro contra Antonio das Mortes, los hombres se enfrentan en el centro del círculo formado por el pueblo sentado. Cada uno de ellos tiene la punta de una bufanda en la boca. En la mano derecha llevan un machete, que utilizan para arremeter contra el otro.

También en ambas películas, Antonio das Mortes es el diablo. La concepción de Dios y Diablo puede 
variar, pero N. Wiener explica que:

Para los maniqueos el diablo es un ser malévolo, es decir, que dirige consciente e intencionalmente su poder contra el hombre; para San Agustín, en cambio, el diablo es la fuerza ciega, entrópica, dirigida sólo objetivamente contra el hombre, a causa de su debilidad y de la ignorancia de éste. Entendiendo, en un sentido amplio, al diablo como aquello que se contrapone a la cultura (Lotman, 1979: 83).

En esa definición se percibe la semejanza del personaje Antonio das Mortes con el anticristo. La ignorancia del jagunço hace que adopte ciertas actitudes a ciegas, solamente interesado en asesinar a cangaceiros. En Antonio Das Mortes, el protagonista comenta al delegado Mattos:

Usted me dice que aún hay un cangaceiro. ¡No me lo puedo creer! Voy a satisfacer su deseo, pero no quiero nada de dinero no. Voy al Jardín de Piranhas para saber si es verdad. $\mathrm{Si}$ aún existe un cangaceiro vivo (Antonio das Mortes en conversación con el Delegado Mattos, Antonio Das Mortes, 1964).

Antonio das Mortes va hasta la ciudad de Jardim de Piranhas para asesinar al cangaceiro Coirana, pues no quiere permitir que ningún cangaceiro viva. Él no acepta el dinero ofrecido por el Coronel Horacio para hacer el trabajo, pues el hecho de matar al último cangaceiro vivo ya es bastante. Después de golpear al cangaceiro, Santa Bárbara coge la mano del protagonista y no deja que éste apuñale a Coirana con un golpe fatal. Antonio das Mortes se enamora de la santa y le pide perdón por sus pecados. Antonio das Mortes dice que hace mucho tiempo busca su lugar en el mundo, pero que después de enamorarse de ella, entiende que su lugar está al lado del pueblo. Esta escena contiene fuertes trazos de ritual y misticismo. El ritual está expresado en la lucha que Rocha denominó como el dragón de la maldad contra el santo guerrero y el misticismo en Santa Bárbara, que perdona los pecados de Antonio das Mortes y lo convierte en protector de los pobres.

\section{Consideraciones finales}

Nelson Motta, en su libro A primavera do dragão (2011), recogía una biografía de la juventud de Glauber de Andrade Rocha. En ella, el escritor constataba que Rocha, desde su adolescencia, ya destacaba por su carácter crítico y por su bagaje literario, que le hacía conocedor de una vasta cultura socióloga y antropológica. Las películas analizadas fueron creadas dentro del espacio semiótico en que el artista lleva a cabo su objetivo principal: exponer la cultura brasileña y criticar la directriz gubernamental. Se da también la burla del sistema social que se halla una vez más en las intenciones del director. Esta afirmación queda demostrada en numerosos hechos: en la simbología, los mitos, el folclore, la intención de filmar la cultura histórica brasileña, y el continuo estado de revolución e inestabilidad en el que se encuentran sus personajes.

El personaje Antonio das Mortes está presente en las dos películas. En Deus e o diabo na terra do sol el personaje es cruel y está marcado por un carácter ambiguo. Diez años después de su encuentro con Manuel y Rosa, Rocha presenta al personaje con una bufanda rosa y modifica sus actitudes. En las dos películas su presencia cataliza la rebelión que lo lleva al "momento de la verdad," y después del cambio, ya no puede volver a ser lo que fue un día. En la película Antonio das Mortes el personaje va más allá de impulsar la rebelión, pues además participa en ella.

La combinación de conocimientos teóricos, culturales y de prácticas del cine propuesta en Deus e o diabo na terra do sol y en Antonio das Mortes muestra sobre todo la rebelión del propio director ante un sistema social inepto y caótico. Ilusionado con el movimiento Cinema Novo y por el deseo de revolución ante de dicho sistema políticosocial, Rocha refleja junto a cultura y el folclore, la rebelión del pueblo que no soporta más subexistir sin lo mínimo necesario para sobrevivir con dignidad (derecho a comida, a salud y a educación). Rocha da voz a los oprimidos, se rebela contra el latifundio y la revolución burguesa. Se observa en ambas películas la intención del director de poner en evidencia una realidad que se escondía en el interior del nordeste de Brasil. 


\section{NOTAS}

'Glauber Rocha, debate 24 de marzo de 1964, transcrito en Viany, 1999: 526.

${ }^{2}$ Comisión Nacional de la Verdad (CNV) es el nombre de una comisión brasileña que investigó las graves violaciones de los derechos humanos que tuvieron lugar entre 18 de septiembre 1946 y 5 de octubre de 1988 en Brasil por agentes estado. El 10 de diciembre de 2014 la CNV presentó su informe final a la presidenta Dilma Rousseff.

${ }^{3}$ Terra em Transe (1967) es una película brasileña, de género dramático, con guion y dirección de Glauber Rocha.

${ }^{4} \mathrm{O}$ movimiento Tropicalismo, Tropicália, fue un movimiento cultural brasileño que surgió bajo la influencia de las corrientes artísticas de la vanguardia y la cultura nacional y extranjera pop (como el pop-rock y el concretismo); manifestaciones tradicionales mixtas de la cultura brasileña a las innovaciones estéticas radicales. Con objetivos conductuales, que se reflejan en gran parte de la sociedad, bajo el régimen militar en la década de 1960 el movimiento se manifestó principalmente en la música (cuyos mayores representantes fueron Caetano Veloso, Gal Costa, Gilberto Gil, Torquato Neto, Os Mutantes y Tom Zé); diversas manifestaciones artísticas, como las artes (especialmente la figura de Hélio Oiticica), el cine (el movimiento fue influenciado e influyó en el movimiento Cinema Novo de Glauber Rocha) y el teatro brasileño (especialmente en obras de José Celso Martínez Corrêa). Uno de los mayores ejemplos del movimiento Tropicália fue una de las canciones de Caetano Veloso, Ilamada precisamente "Tropicália".

\section{REFERENCIAS BIBLIOGRÁFICAS}

ALMEIDA, J. F. A Bíblia Sagrada, O Novo Testamento. São Paulo: Grupo de Estudos Bezerra de Menezes.

ALMEIDA, J. F. A Bíblia Sagrada, O Antigo Testamento. São Paulo: Grupo de Estudos Bezerra de Menezes.

AVELLAR, J. C. (2002). Glauber Rocha. Madrid: Ediciones Cátedra/Filmoteca Española.

AVELLAR; J. C. (org.). O Processo Do Cinema Novo. Rio de Janeiro: Aeroplano Editora.

BAJTíN, M. (1987). La cultura popular en la Edad Media y en el Renacimiento. El contexto de François Rabelais. Madrid: Alianza Universidad.

CARMONA, R. (s/d). Cómo se comenta un texto fílmico. Madrid: Cátedra.

CASETTI, F. (1980). Introducción a la semiótica. Barcelona: Fontanela.

ECO, U. (2010). El nombre de la rosa. Formato Digital:
Fotocomposición 2000, S.A

ECO, U. (s/d). Los límites de la interpretación. Barcelona: Lumen.

ECO, U. (s/d). Tratado de semiótica general. Barcelona: Lumen.

FOUCAULT, M. (1971). El orden del discurso. Paris: Éditions Gallimard.

FOUCAULT, M. (1971). La historia de la sexualidad I, la voluntad de saber. España: Siglo veintiuno editores.

GERBER, R. (1991). Glauber Rocha E A ExperiêNcia Inacabada Do Cinema Novo. En: GOMES, P. E. S. et al. Glauber Rocha. $3^{3}$ ed. São Paulo: Paz e Terra.

LÉVI-STRAUSS, C. (1987). Mito y significado. Madrid: Alianza Editorial, S. A

LÉVI-STRAUSS, C. (1964). Mitológicas: lo crudo y lo cocido. Paris: Librairie Plon.

LOTMAN, Y. M. (1996). Semiosfera. Tomos I y II. Madrid: Cátedra.

LOTMAN, Y. M. (2000). La Semiosfera III. Semiótica de las artes y de la cultura. Madrid: Cátedra

LOZANO, J. (1979). J. M. Lotman y Escuela de Tartu. Semiótica de la Cultura, Introducción, Selección y Notas. Madrid, Ed. Cátedra.

LOTMAN, Y. M. y La Escuela de Tartu. (1979). Semiótica de la cultura. Madrid: Cátedra.

NEMER, S. R. B. (2006). A função intertextual do cordel no cinema de Glauber Rocha. Porto Alegre: Famecos/PUCRS, n 15 .

ROCHA, G. (1981). Revolução do cinema novo. Rio de Janeiro.

ROCHA, G. (1963). Revisão crítica do cinema brasileiro. Rio de janeiro: Imago.

ROCHA, G. (1967). Una estética de la violencia. Marcha, n¹374. Montevideo.

ROCHA, G. (1971). Eztetyka do Sonho. Columbia University, New York.

SAUSSURE, F. (1987). Curso de lingüística general. Madrid: Alianza.

TOLENTINO, C. (2001). Deus e o diabo na terra do sol, o rural no cinema brasileiro. São Paulo: UNESP.

VIANY, A. (1993). Introdução ao cinema brasileiro. Rio de Janeiro: Revan.

VIÑAS PIQUER, D. (2002). Historia de la crítica literaria. Barcelona: Ariel. pp. 462-468.

XAVIER, I. (2001). Cinema Brasileiro Moderno. São Paulo: Paz e Terra. 
XAVIER, I. (1983). Sertão mar: Glauber Rocha e a estética da fome. São Paulo: Embrafilme/Secretaria da Cultura/MEC/ Editora Brasiliense.

\section{Películas}

ROCHA, G. (1964). (Filme-vídeo). Deus e o Diabo na terra do sol. Produção Glauber Rocha, Rio de Janeiro. 1 DVD, 125min. Preto e Branco. Som.

ROCHA, G. (1969). (Filme-vídeo). O dragão da Maldade contra o Santo Guerreiro (Antonio das Mortes). Produção Glauber Rocha, Rio de Janeiro. 1 DVD, 100min. Color. Som.

\section{Documentales}

Cana ILB. Entrevista con Rogério Costa Rodrigues sobre el Cinema Novo. Publicado en 23/11/2012. Recuperado de [http://youtu.be/f1SANa8WL38]. Consultado [11/11/2014]. 